\title{
Understanding the Complexity of Business Information Dissemination in Social Media: A Meta-Analysis of Empirical Evidence from China
}

\author{
Jiawen Yan $\left(\mathbb{D}\right.$, Yuantao You $\left(\mathbb{D}\right.$, Yu Wang $\mathbb{D}^{D}$, and Dongfang Sheng $(\mathbb{D}$ \\ School of Management, Shandong University, Jinan 250100, China \\ Correspondence should be addressed to Dongfang Sheng; dfsheng@sdu.edu.cn
}

Received 14 May 2021; Accepted 17 June 2021; Published 29 June 2021

Academic Editor: Baogui Xin

Copyright (c) 2021 Jiawen Yan et al. This is an open access article distributed under the Creative Commons Attribution License, which permits unrestricted use, distribution, and reproduction in any medium, provided the original work is properly cited.

\begin{abstract}
With the development of social networks, the complexity of the factors affecting the users' information dissemination is increasing and the complexity of online social networks and influencing factors of individual behaviors and attitudes make the development of online public opinion present a dynamic, complex, and multifactor evolution. Analyzing the influencing factors of public opinion dissemination is conducive to optimize company management and information diffusion management. However, there has been no comprehensive analysis of the complex factors that influence the dissemination of information; this study focused on synthesizing 20 empirical studies on the influencing factors of China public opinion dissemination from the perspective of the user, and a meta-analysis was conducted. We establish the influencing factors of users' information adoption model from three aspects of information source reliability, perceived information quality, and the heat of public opinion events based on elaboration likelihood model. The results indicated that the main influencing factors of public opinion communication are authority, reliability, quality of information form, quality of information editing, quality of information utility, and event attendance preference. Among the factors, authority and quality of information editing have more significant impacts on users' information adoption behavior in the dissemination of public opinion. In addition, whether the type of event was a public emergency had a moderating effect. The results are helpful to explore the universality of the influencing factors so as to help related regulators better build a multiangle supervision mechanism and conduct early warning of information diffusion.
\end{abstract}

\section{Introduction}

With the rapid development of online social networks, various types of social media communication platforms and information dissemination platforms are constantly emerging, and people participate in public opinion discussions in a variety of ways. The development of the Internet has provided new platforms for the formation and dissemination of public opinion. Social networks have become the main channel for the dissemination of public opinion [1]. Users are no longer limited by time and space. Currently, they can participate in the discussion and dissemination of public opinions through social networks at anytime and anywhere.

While the growth of online social platforms can yield many benefits, some hidden dangers also exist. Online public opinion has a low threshold for participation and fast fermentation speed, which easily breeds false and harmful information. Once negative public opinion information is spread out of control or even evolves into a public opinion crisis, it will bring serious challenges to social security and stability. Therefore, how to effectively obtain public opinion and give full play to the role of media, opinion leaders, and the government on the basis of safeguarding citizens' freedom of speech and construct multiangle supervision mechanism to realize the maintenance and construction of benign public opinion ecology is an important issue that people should concerned about. In addition, in the commercial field, public opinion information provides an important reference for enterprise product research and development, marketing, brand building, and so on and plays an extremely important role in crisis management, 
creating economic value that cannot be ignored for enterprises.

For the past few years, compared with the traditional sociological perspective and communication perspective, the proportion of literature studies on public opinion studies using complex networks has significantly increased. A large number of empirical studies have shown that small-world networks and scale-free networks can reasonably and accurately describe the communication networks in the real world [2]. At the same time, the network groups that participate in the communication of public opinion are unstable. In the evolution process of public opinion, the change of microindividual attitude in the network is affected by a variety of factors. Therefore, the complexity of online social networks and the complexity of the influencing factors of individual behaviors and attitudes make the development of online public opinion present a dynamic, complex, and multifactor evolution.

In recent decades, there has been an increasing number of studies in the field of public opinion spread. These studies mainly involve the mechanisms, evolutionary mechanisms, governance, and characteristics of public opinion spread. Additionally, the influencing factors of public opinion dissemination have gradually become a hot topic. As early as the last century, Shannon pointed out in his information theory that the communication process of public opinion is affected by four elements, that is, the information source, trust, information, and channel [3]. In recent years, scholars in China have conducted abundant empirical studies on the influencing factors of public opinion dissemination. Researchers and organizations have sought the factors that influence public opinion dissemination, thereby ultimately provided a theoretical basis for the control of public opinion. Zhang et al. built a model from the perspective of information source characteristics and information form and studied the dissemination of public opinion on Sina Weibo [4]. It was concluded that the characteristics of information sources were the main influencing factor, the number of followers played a mediating role, and the related factors of information form had no significant influence. Yin conducted an empirical study on the influencing factors of WeChat public platform information dissemination, and the results showed that the heat of articles was correlated with the theme, push time, and title characteristics to a certain extent [5]. Based on the perspective of consumers, Zhang concluded that the professionalism of negative public opinion communicators and the network involvement of receivers influence the repurchase intention of passengers through the perceived usefulness and perceived risk of public opinion [6]. Liao et al. combined the $5 \mathrm{~W}$ communication mode of Harold Lasswell and agenda-setting theory to propose hypotheses of information dissemination factors and found that opinion leaders had the greatest influence on the spread effect among communication groups, the attributes of Weibo publishers were positively correlated with the spread effect, and the amount of information was negatively correlated with the communication effect [7]. Gu et al. based on expectation confirmation theory, online trust theory, and immersion theory integrally proposed that users' perceived usefulness of public opinion, online trust, the convenience of link sharing, and other factors are related to users' willingness to spread public opinion [8]. In addition, according to the perspective of information ecology, Zhao concluded through relevant analysis that the information environmental heat, information preference, information technology preference, and the influence of microblog public opinion information personnel in the new media environment would positively influence the communication situation of microblog public opinion in the new media environment [9].

Although there have been numerous empirical studies on the influencing factors of public opinion dissemination over the past decade, most of them did not reach a consensus due to the complexity of the public opinion communication network and the complexity of the influencing factors of user behavior, and there are few comprehensive analyses of different research conclusions. This resulted in inconsistency among the existing independent empirical research results in this research direction. Therefore, we used meta-analysis to comprehensively analyze the results of previous empirical studies. Meta-analysis is a research method that forms a consistent conclusion and promotes the longitudinal development of research by summarizing and synthesizing existing multiple conclusions and further theoretical results [10]. Meta-analysis is a scientific research method used to summarize and evaluate existing research results. Compared with traditional literature reviews, a meta-analysis takes each research as a sample, and it can identify heterogeneity between multiple research results, integrate the research results, improve the accuracy of the test results, reduce the subjectivity of the research, and allow more objective conclusions to be drawn.

In view of this, using the meta-analysis method to synthetically analyze different research conclusions about factors affecting the spread of public opinion from the perspective of the user is of practical importance.

Therefore, to address their limitations and to the differences in the degree and direction of different research results, this article collects China and builds a users' public opinion information adoption behavior model based on the elaboration likelihood model to explore the general factors affecting public opinion dissemination and promote the indepth development of research on the influencing factors of public opinion dissemination. A meta-analysis of the literature was conducted to comb and reanalyze the relevant empirical studies in this field and integrate a large volume of results to determine whether the research findings were homogeneous. We aimed to achieve the following goals:

(1) Propose relevant hypotheses about the influencing factors of users' information adoption behavior in public opinion spread based on the existing relevant literature, quantitatively combine the independent research results through a meta-analysis, and then qualitatively test the hypotheses.

(2) Examine the convergence or divergence of published research results by conducting a quantitative metaanalysis and try to analyze and explain the 
controversial conclusions with large samples and universal adaptability. Discuss the factors influencing the universality of network public opinion communication from the perspective of quantitative research, discover the social and economic value of public opinion information, and provide valuable theoretical reference and practical reference for the government as well as enterprises to adjust and optimize the risk management mode of public opinion information.

(3) Explore the moderating variables that may influence the research results and provide new insights for future research.

\section{Theoretical Background and Hypotheses}

2.1. Definition of Information Adoption Behavior. The concept of information adoption comes from technology adoption theory, which has gradually become a hotspot in the field of library and information science. With the expansion and development of technology adoption theory, studies on users' information adoption behavior are gradually enriched. At present, there is no unified definition of information adoption behavior among scholars. Cheung et al. [11] gave a simple descriptive description of information adoption and information adoption behavior in their discussion; that is, "information adoption is a process in which people make purposeful use of information. Information adoption behavior is one of the main behaviors that users seek behavior guidance in virtual groups." Song believes that information adoption is a decision-making process in which users take the initiative to select and judge information based on their own needs and finally make a decision about whether to adopt the information [12]. Geng proposes that information adoption is the selection and evaluation of information as well as the absorption and utilization of information [13]. This paper holds that, in the field of public opinion spread, information adoption refers to the behavior that users make choices and judgments on complex and changeable public opinion information, and they adopt it based on the recognition of the utility of the information. Information adoption includes the following forms: information forwarding, comments, thumbs-ups, and so on.

2.2. Elaboration Likelihood Model. In empirical research on users' information adoption behavior, the theories include the technology acceptance model, rational behavior model, information adoption model (IAM), elaboration likelihood model, and others. The ELM is the most representative model for explaining the intention to adopt information, which has been supported by a large number of empirical studies. The elaboration likelihood model (ELM) originated from research in the field of social psychology. As a persuasion model, it has been widely used in research on attitude, social communication, and consumer behavior. The model assumes that there is a possibility interval of fine machining when information receivers process persuasive appeals, and one of the fundamental dimensions of information processing and attitudes is the depth and quantity of the information processing. In this paper, the ELM is used to analyze and explain the factors that affect users' information adoption behavior in public opinion dissemination. In the ELM, the process by which people change their attitude and behavior under the influence of an information source is described using two information processing paths, namely, the central route and peripheral route $[14,15]$. The central path refers to the process in which the information receiver needs to change his or her attitude or behavior after thorough reading and high effort thinking about the characteristics of the information. Information traits are mainly related to a series of qualities of the information content such as its novelty and objectivity. For example, consumers carefully analyze and summarize the information content provided by product advertisements instead of forming purchase decisions based on the attractiveness of advertising spokespersons [16]. The marginal path refers to the process in which the information receiver changes his attitude or behavior by investing a little energy and time in the peripheral clues related to the problem and thinking with low effort. Information peripheral cues are mainly related to the characteristics of information sources, such as the reliability and authority of information sources, which can be used as peripheral cues to cause attitude changes under certain circumstances [11].

Based on the above, the elaboration likelihood model process is shown in Figure 1.

2.3. Models and Hypotheses. According to the ELM, users' information adoption behavior is jointly affected by the quality of the information content and the characteristics of the information sources [14]. In addition, research has suggested that people's motivation to forward popular microblogs is greater than that to forward ordinary microblogs and that the duration of the influence of popular microblogs is longer than that of ordinary microblogs [17]. Additionally, according to the research, the length of time that the microblog information spreads is related to the degree to which it is convenient for Internet users to obtain the information. If users can more easily obtain the information, this information can have a more continuous influence [18]. Therefore, public opinion events with high heat equivalent in the spotlight in the field of public opinion contain information that is easier for netizens to pay attention to and obtain. Based on this, we considered the heat angle of public opinion events to more comprehensively study the factors affecting users' information adoption behavior. Since people's attention preference for hot events is based on simple reasoning and judgment and they do not spend much time and energy on cognition and thinking, this variable is included in the edge path of the ELM.

2.3.1. The Influence of Information Source Reliability on Users' Information Adoption Behavior. Information source reliability refers to the degree of trust of information receivers in information sources [19], and it can be used as an 


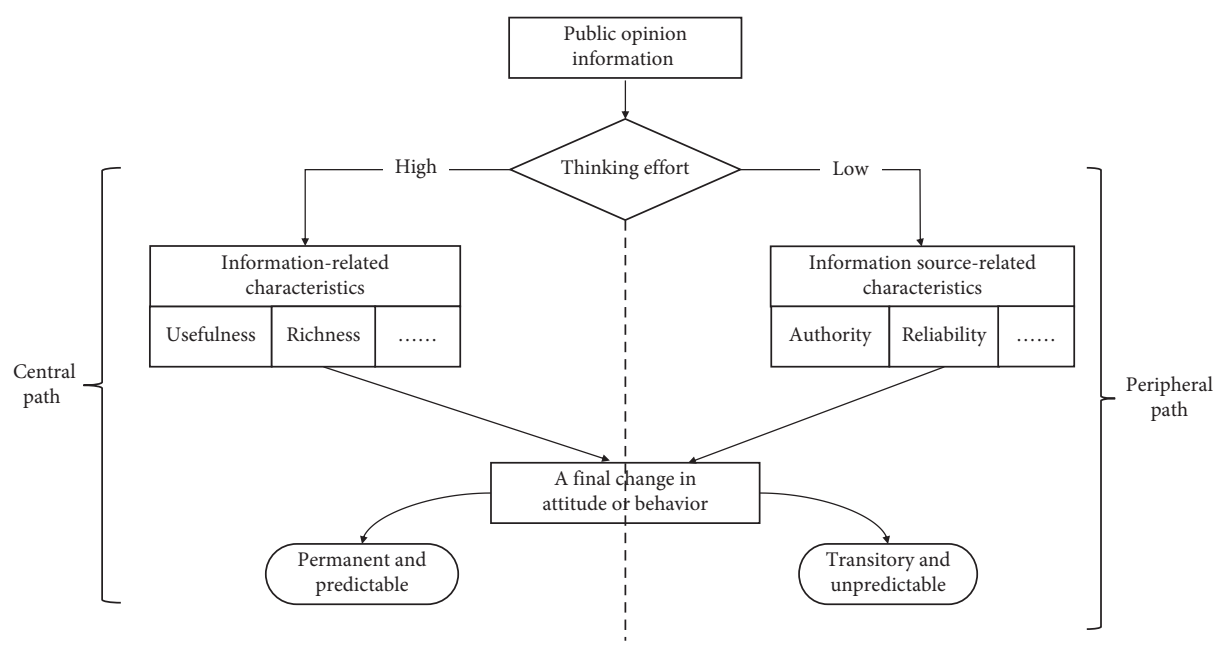

FIgURE 1: The elaboration likelihood model process.

important reference index of information persuasion. Research on source reliability mainly involves authority and reliability. According to existing studies, source reliability has a significant impact on the persuasion process. Under the condition of consistent information content, individuals are more likely to be persuaded when the source is highly reliable [20]. In addition, some studies have shown that authority and professionalism are important factors for celebrities to be more easily noticed and sought [21, 22]. The professionalism of bloggers is closely related to their reliability, which is an important screening mechanism for users for a large number of blog posts [15]. The authority of the information source includes authentication, identity type and the reliability of the information source. Authority refers to the trustworthiness of the information publisher perceived by the audience. Many scholars regard the number of followers as an important factor for representing the effect of information communication [23, 24], as well as the account level, which is mainly judged by the identity of an opinion leader. Therefore, we formulated the following hypotheses:

$\mathrm{H} 1$ : the authority of the information source is positively related to the information adoption behavior of users $\mathrm{H} 2$ : the reliability of the information source is positively related to the information adoption behavior of users

2.3.2. The Influence of Perceived Information Quality on Users' Information Adoption Behavior. The central path in the ELM mainly involves the judgment of the information quality. Information quality is generally related to the characteristics of the information content itself, such as the novelty and objectivity of the information [11]. Previous studies have shown that perceived information quality positively influences users' willingness to communicate [25]. Information quality is generally related to the characteristics of the information content. This paper divides information quality into three categories: information form quality, information editing quality, and information utility quality.
Information form quality refers to the information content features that can meet the information needs of the public and bring value to the public, including the richness of the information, such as whether there are videos, pictures, and microtopics. Studies have found that rich information forms contribute to readers' perception and memory of information [17], thus increasing the readability of information content and ultimately stimulating users' information adoption and sharing behavior. The information editing quality can be measured by the formality of the information editing format, and the professionalism of information editing and publishing can make the information more credible, including the integrity and reliability of the information. Information utility quality refers to the public's evaluation of whether event information can meet their needs and the information receivers' experience and perception of the information value. Specific measurement indexes include the usefulness (the gap between the information content and the public's expectations), timeliness, and relevance (the information is related to the public's purposes of use).

Consistent with this, our meta-analysis tested the following hypotheses:

H3: information form quality is positively related to users' information adoption behavior

$\mathrm{H} 4$ : information editing quality is positively related to users' information adoption behavior

$\mathrm{H} 5$ : information utility quality is positively related to users' information adoption behavior

2.3.3. Influence of the Heat of Public Opinion Events on Users' Information Adoption Behavior. The heat of a public opinion event refers to the overall attention to and degree of discussion of the event in the information environment. In this paper, the heat of public opinion events is divided into two dimensions: event attention preference and information environment heat. Research shows that microaffairs with different themes cause different scales of forwarding and 
attention [26]. In addition, through intercepting a week's microblogs and classifying their nature, some studies have found that fresh event information accounted for the highest proportion (33\%) [27]. The extent to which the public prefers to pay attention to events often affects their behavior of expressing their opinions, thoughts, or emotions. The heat of the information environment refers to the heat of the social discussion on events. Hot events are more likely to arouse users' interest. For example, on microblogging platforms, hot microblogs and hot search topics are more likely to attract users' attention and participation [17].

Based on this, we tested the following hypotheses:

H6: event attention preference is positively related to users' information adoption behavior

H7: the heat of the information environment is positively related to the information adoption behavior of users

2.3.4. The Moderating Effect of the Types of Public Opinion Events. In the literature included in the meta-analysis, we noticed that the types of sample events in some studies were public emergencies, such as natural disasters, public health events, and social security events. According to the Emergency Response Law of the People's Republic of China, emergency events refer to natural disasters, accidents, disasters, public health events, and social security events that occur suddenly, cause or may cause serious social harm, and require emergency measures. Due to the particularity of public emergencies, users' adoption behaviors for public opinion information about these events may be different from those for public opinion information about ordinary events. Event type factors add a certain complexity to the study of users' information adoption behavior, while the occurrence of various emergencies brings severe challenges to the development of the country, society, and enterprises themselves. In the field of economics and business, the impact of public emergencies cannot be ignored. The response to emergencies is an important work that every enterprise should pay attention to, and it is also a problem about emergency management that should explore and solve. When an emergency occurs, the enterprise should timely understand the demands of users, effectively use diversified information communication channels to output information, do a good job in public opinion management of the emergency to control the impact and loss to a minimum, and provide public opinion guarantee for the high-quality development of the enterprise. Therefore, the study of this regulatory variable has a certain theoretical value for improving the emergency management level and crisis public relations level of enterprises. At present, there is generally a lack of studies investigating the effect of the type of public opinion event on users' information adoption. Thus, in this study, we considered the effect of the type of public opinion event and specifically addressed this moderator. We formulated an exploratory question:
Does the type of public opinion event (whether it is a public emergency or not) have an impact on the adoption of public opinion information?

Based on the above analysis and hypotheses, the influencing factors model of public opinion dissemination proposed in this study is shown in Figure 2.

\section{Method}

3.1. Meta-Analysis. Meta-analysis is a reanalysis of the results of multiple independent studies on the same issue to form a consistent conclusion by integrating the findings of these independent studies. Glass defined meta-analysis in 1976 as "a statistical method that systematically and quantitatively integrates previous research results" [28]. Meta-analysis is a research method that promotes the longitudinal development of research by summarizing and synthesizing existing conclusions and further theoretical results [10]. Meta-analysis was initially used in clinical research. As a scientific research method used to summarize and evaluate existing research results, it has been gradually applied to comprehensive research in all research directions because it allows integration of existing research and analysis of common characteristics.

Compared with traditional literature reviews, a metaanalysis takes each research as a sample, and it can identify heterogeneity between multiple research results, integrate the research results, improve the accuracy of the test results, reduce the subjectivity of the research, and allow more objective conclusions to be drawn.

3.2. Search Strategy. The research object of our study is the influencing factors of users' information adoption behavior in the dissemination of public opinion. To ensure the reliability and completeness of the research, two retrieval methods were used to identify eligible research. First, journal articles and doctoral dissertations, the subject and keywords of which include "public opinion spread," were included; additionally, we scanned the bibliographies of these journal articles and dissertations. A total of 936 core journal articles and CSSCI (Chinese Social Sciences Citation Index) papers and 1587 master's theses and doctoral dissertations were identified. Second, the key elements in the search and selection process were the following: "public opinion dissemination," "public opinion spread," and "information adoption." Wanfang Database (https://www.wanfangdata. com.cn/index.html) and CNKI (https://www.cnki.net) are the most professional academic databases in China, and they are the most important information sources for understanding the academic trends in China. So we searched the Wanfang and CNKI databases for any combination of these terms and the key elements and also scanned the bibliographies of the identified articles to find additional research. After a thorough screening of the titles, abstracts, and keywords, 41 articles that met the subject criteria were obtained.

The following guidelines were followed to select studies:

(1) Studies were chosen if they involved empirical research on users' information adoption behavior in the dissemination of public opinion 


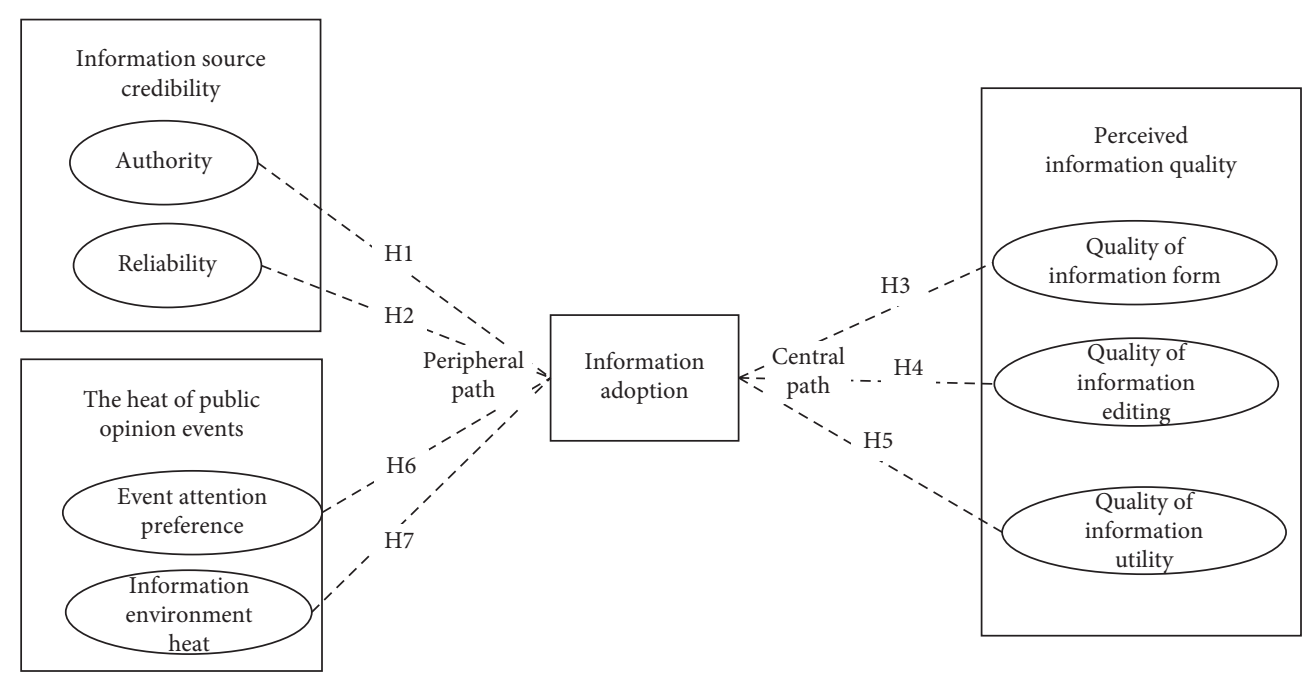

FIGURE 2: Influencing factor model of users' information adoption behavior in public opinion spread.

(2) To ensure the independence of each study, if two or more studies reported in different articles, proceedings papers, and dissertations were based on the exact data set, they were treated as one study, and only one article was selected

(3) Studies were chosen if users' information adoption behavior was the dependent variable of the research

(4) Studies were chosen if they reported correlations among influencing factors and sample size or correlation coefficients and $p$ values or $t$-values and sample sizes, which can be converted to correlations

(5) We eliminated studies with unclear descriptions and unreasonable variable designs

After rigorous screening, 20 articles were selected for research. The sample included 9 academic journal articles and 11 master's theses and doctoral dissertations. We selected 20 independent studies that generated 20 samples and obtained the $t$-values and sample sizes from 3 studies. The correlation coefficients and sample sizes were obtained with formulas.

3.3. Coding. After 20 independent studies were obtained, the study was encoded in 7 aspects (code number, publication, literature resource, number of variables, sample size, effect size, and event type). In addition, there were differences in the results of different studies. In the coding process, we should note the following: (1) The generation of effect value is based on independent samples, and each independent sample is encoded once. If a study contains more than one independent sample, the corresponding multiple coding is carried out. (2) If only the upper or lower concepts of influencing factor variables and users' information adoption behaviors were listed in the literature, we obtained the required effect size by averaging the data [29]. In this study, the same authors were used to reencode all the coding literature studies at different time periods, and then the coding results at different time periods were compared, and it was found that there was no difference except for the deviation of some data. This indicates that the coding of this study has a high degree of consistency.

The detailed coding information is shown in Table 1.

3.4. Variable Design. In this study, through the analysis of variables in the selected 20 articles combined with analysis of relevant literature on information source reliability (authority and reliability), perceived information quality (information form quality, information editing quality, and information utility quality), and the heat of public opinion events (event attention preference and information environment heat), we identified variables with slight conceptual differences in the literature.

The description of the final relevant variables is shown in Table 2 .

3.5. Meta-Analysis Procedures. For statistical analyses, we used Comprehensive Meta-Analysis software. We adopted the following procedure: (1) We used the correlation coefficients from the original literature as the effect size. For other pieces of literature, we extracted the $t$-value and the total number of individuals from the samples $(N)$ to determine the final effect size. (2) We used the fixed effect model or random effect model to evaluate the correlation coefficients between the influencing factors of public opinion dissemination behavior and users' information adoption behavior. (3) We calculated confidence intervals. A significant correlation was one where the confidence interval did not include 0. (4) We used Egger's method to evaluate whether there was publication bias in the included literature. (5) Finally, in order to determine whether there was a moderator, we used the $75 \%$ rule, which holds that, after considering all statistical artifacts, if there is still a variance of $25 \%$ or an observed effect size, a moderator must exist.

\section{Results}

4.1. Heterogeneity Test. The heterogeneity test is an essential part of a meta-analysis. Heterogeneity refers to the 
TABle 1: A detailed overview.

\begin{tabular}{|c|c|c|c|c|c|c|}
\hline $\begin{array}{l}\text { Code } \\
\text { number }\end{array}$ & Publication & Literature resource & $\begin{array}{l}\text { Number of } \\
\text { variables }\end{array}$ & $\begin{array}{l}\text { Sample } \\
\text { size }\end{array}$ & Effect size & $\begin{array}{l}\text { Is it a public } \\
\text { emergency? }\end{array}$ \\
\hline 1 & Wei [30] & Master's thesis & 4 & 480 & $\begin{array}{c}\text { Correlation } \\
\text { coefficient and } N\end{array}$ & Yes \\
\hline 2 & Han [31] & Master's thesis & 10 & 700 & $\begin{array}{l}\text { Correlation } \\
\text { coefficient }\end{array}$ & No \\
\hline 3 & Zhang [6] & Master's thesis & 5 & 182 & N & Yes \\
\hline 4 & Gu et al. [8] & Information science & 7 & 616 & $\begin{array}{l}\text { Correlation } \\
\text { coefficient }\end{array}$ & No \\
\hline 5 & Zeng [32] & Information science & 9 & 649 & $N$ & No \\
\hline 6 & Wang [33] & China youth study & 4 & 2745 & $\begin{array}{l}\text { Correlation } \\
\text { coefficient }\end{array}$ & No \\
\hline 7 & $\begin{array}{l}\text { Zhao and } \\
\text { Cheng }[25]\end{array}$ & $\begin{array}{l}\text { Journal of the China Society for } \\
\text { Scientific and Technical Information }\end{array}$ & 8 & 420 & $N$ & No \\
\hline 8 & Huang [34] & Master's thesis & 11 & 170 & $\begin{array}{l}\text { Correlation } \\
\text { coefficient }\end{array}$ & No \\
\hline 9 & Zhang [35] & Master's thesis & 4 & 343 & $N$ & Yes \\
\hline 10 & $\mathrm{Wu}[36]$ & Master's thesis & 9 & 148 & $\begin{array}{l}\text { Correlation } \\
\text { coefficient }\end{array}$ & No \\
\hline 11 & Zhao [9] & Master's thesis & 4 & 235 & $N$ & Yes \\
\hline 12 & Chen [37] & Master's thesis & 8 & 420 & $\begin{array}{l}\text { Correlation } \\
\text { coefficient }\end{array}$ & Yes \\
\hline 13 & Hong [38] & $\begin{array}{l}\text { China Population, Resources and } \\
\text { Environment }\end{array}$ & 6 & 10405 & $p$ value and $N$ & No \\
\hline 14 & Cao [39] & Chinese Journal of Computers & 6 & 12284 & $\begin{array}{c}\text { Correlation } \\
\text { coefficient and } N\end{array}$ & No \\
\hline 15 & Zhang et al. [4] & $\begin{array}{l}\text { Information and Documentation } \\
\text { Services }\end{array}$ & 7 & 598 & $T$-value and $N$ & Yes \\
\hline 16 & Liao et al. [7] & $\begin{array}{l}\text { Information and Documentation } \\
\text { Services }\end{array}$ & 2 & 24500 & $\begin{array}{l}\text { Correlation } \\
\text { coefficient }\end{array}$ & Yes \\
\hline 17 & Hou [40] & Discovering value & 3 & 213 & $N$ & No \\
\hline 18 & Wang [41] & Master's thesis & 11 & 185 & $\begin{array}{l}\text { Correlation } \\
\text { coefficient }\end{array}$ & No \\
\hline 19 & $\mathrm{Wu}[42]$ & Master's thesis & 4 & 291 & $N$ & No \\
\hline 20 & Wang [43] & Master's thesis & 10 & 295 & $\begin{array}{l}\text { Correlation } \\
\text { coefficient }\end{array}$ & No \\
\hline
\end{tabular}

intergroup variance between groups of studies. The greater the proportion of intergroup variance to total variance, the greater the heterogeneity between studies. This study used the Q-test to determine whether the included literature was homogeneous. When $p<0.05$, there was heterogeneity in the study [44]. If the research results were heterogeneous, the random effects model was adopted. The research results were homogeneous if the results obtained by the fixed effects model and the random effects model were consistent.

The results of this study are shown in Table 3. All the above assumptions have heterogeneity $(p<0.001)$. In summary, after the $Q$-test was performed, we adopted the random effects model analysis method.

4.2. Main Results. Table 4 reports the meta-analysis results of the factors influencing user public opinion spread behavior under the random effect model. First, $\mathrm{H} 1$ and $\mathrm{H} 2$ posit that authority and reliability, respectively, have a significant positive correlation with users' information adoption behavior in the dissemination of public opinion. These hypotheses are supported by the results (H1, $r=0.484$, $p<0.001 ; \mathrm{H} 2, r=0.454, p<0.01)$. Authority (H1, $r=0.484$ ) has the greatest impact on users' public opinion spread behavior. However, reliability $(\mathrm{H} 2, r=0.454)$ has little impact on user public opinion spread behavior, but its impact is significant. Therefore, $\mathrm{H} 1$ and $\mathrm{H} 2$ are verified.

Second, in terms of perceived information quality, the relationships between the quality of information form and quality of information editing and users' information adoption behavior in the dissemination of public opinion are stronger than the relationship between the quality of information utility and users' information adoption behavior (H3, $r=0.472, p<0.001 ; \mathrm{H} 4, r=0.537, p<0.001 ; \mathrm{H} 5$, $r=0.459, p<0.01$ ).

Finally, regarding the heat of public opinion events, H6 predicts that the impact of event attention preference and users' information adoption behavior will be greater in the spread of public opinion. The hypothesis is supported (H6, $r=0.483, p<0.01)$. Conversely, $\mathrm{H} 7$ is not supported by sufficient evidence $(\mathrm{H} 7, r=0.415, p=0.117>0.05)$. In the dissemination of public opinion, the information environment has no significant impact on users' information adoption behavior, and there is no relationship between 
TABLE 2: The description of the relevant variables.

\begin{tabular}{|c|c|c|c|c|}
\hline $\begin{array}{l}\text { Information processing } \\
\text { route based on the ELM }\end{array}$ & Second index & Third index & Variable explanation & $\begin{array}{c}\text { Source } \\
\text { documents }\end{array}$ \\
\hline \multirow[t]{2}{*}{ Peripheral route } & \multirow{2}{*}{$\begin{array}{l}\text { Information source } \\
\text { reliability }\end{array}$} & Authority & $\begin{array}{c}\text { The authority of information sources, including } \\
\text { identity authentication, identity type, and source } \\
\text { reliability. }\end{array}$ & {$[45,46]$} \\
\hline & & Reliability & $\begin{array}{l}\text { Reliability of information publishers felt by the } \\
\text { audience, including fans and account levels. }\end{array}$ & {$[45,47]$} \\
\hline \multirow{3}{*}{ Central route } & \multirow{3}{*}{$\begin{array}{l}\text { Perceived } \\
\text { information quality }\end{array}$} & $\begin{array}{l}\text { Quality of } \\
\text { information form }\end{array}$ & $\begin{array}{l}\text { The characteristics of information content, including } \\
\text { the richness of information such as videos, pictures, } \\
\text { and microtopics, can meet public information needs } \\
\text { and bring value to the public. }\end{array}$ & {$[48,49]$} \\
\hline & & $\begin{array}{l}\text { Quality of } \\
\text { information } \\
\text { editing }\end{array}$ & $\begin{array}{l}\text { Measured by the formality of the information editing } \\
\text { format. Professional information editing and } \\
\text { publishing can make information more credible. It } \\
\text { contains information integrity and reliability. }\end{array}$ & {$[49-51]$} \\
\hline & & $\begin{array}{l}\text { Quality of } \\
\text { information utility }\end{array}$ & $\begin{array}{l}\text { The public's evaluation of whether their information } \\
\text { needs are met. Specific measurement indicators } \\
\text { include usefulness (the gap between information } \\
\text { content and public expectations), timeliness, and } \\
\text { relevance (information is related to the purpose of } \\
\text { public use). }\end{array}$ & {$[50,51]$} \\
\hline \multirow[t]{2}{*}{ Peripheral route } & \multirow{2}{*}{$\begin{array}{c}\text { The heat of a public } \\
\text { opinion event }\end{array}$} & $\begin{array}{l}\text { Event attention } \\
\text { preference }\end{array}$ & $\begin{array}{l}\text { The public's preference for events can often affect } \\
\text { their behaviors that express their opinions, ideas, or } \\
\text { emotions. }\end{array}$ & {$[52,53]$} \\
\hline & & $\begin{array}{l}\text { Information } \\
\text { environment heat }\end{array}$ & $\begin{array}{c}\text { Social discussion of events. Hot events can arouse } \\
\text { users' interest. }\end{array}$ & {$[49,53,54]$} \\
\hline
\end{tabular}

TABLE 3: Q-test.

\begin{tabular}{|c|c|c|c|c|c|c|c|c|c|c|c|c|}
\hline & \multirow[t]{2}{*}{ Variable } & \multirow[t]{2}{*}{$K$} & \multirow[t]{2}{*}{$N$} & \multicolumn{3}{|c|}{$Q$-test } & \multicolumn{3}{|c|}{ Tau-squared } & \multicolumn{3}{|c|}{$\begin{array}{l}\text { Egger regression } \\
\text { intercept }\end{array}$} \\
\hline & & & & $Q$ value & $p$ value & $I^{2}$ & Tau-squared & SE & Variance & Tau & Coef. & $p$ \\
\hline $\mathrm{H} 1$ & Authority & 1 & 14721 & 1189.071 & $\leq 0.001$ & 99.159 & 0.164 & 0.118 & 0.014 & 0.405 & 7.089 & 0.172 \\
\hline $\mathrm{H} 2$ & Reliability & 6 & 27212 & 3895.015 & $\leq 0.001$ & 99.862 & 0.237 & 0.221 & 0.049 & 0.487 & -20.618 & 0.378 \\
\hline $\mathrm{H} 3$ & Quality of information form & 3 & 11173 & 91.296 & $\leq 0.001$ & 97.809 & 0.165 & 0.176 & 0.031 & 0.46 & 11.863 & 0.591 \\
\hline $\mathrm{H} 4$ & Quality of information editing & 4 & 1037 & 158.575 & $\leq 0.001$ & 98.108 & 0.219 & 0.191 & 0.036 & 0.468 & 7.44812 & 0.7345 \\
\hline H5 & Quality of information utility & 8 & 2675 & 849.357 & $\leq 0.001$ & 99.176 & 0.375 & 0.221 & 0.049 & 0.613 & -27.679 & 0.089 \\
\hline H6 & Event attention preference & 2 & 840 & 44.137 & $\leq 0.001$ & 97.734 & 0.103 & 0.150 & 0.022 & 0.322 & - & - \\
\hline H7 & Information environment heat & 3 & 678 & 268.885 & $\leq 0.001$ & 99.256 & 0.621 & 0.640 & 0.409 & 0.788 & 12.953 & 0.877 \\
\hline
\end{tabular}

TABLE 4: Results of the meta-analysis.

\begin{tabular}{lcccccccc}
\hline & \multirow{2}{*}{ Variable } & $K$ & $N$ & \multicolumn{2}{c}{ Effect size and 95\% CI } & \multicolumn{2}{c}{ Two-tailed test } \\
& & & & Point estimation & Lower & Upper & $Z$ value & $p$ value \\
\hline H1 & Authority & 11 & 14721 & 0.484 & 0.243 & 0.624 & 3.978 & $\leq 0.001$ \\
H2 & Reliability & 2 & 27912 & 0.454 & 0.165 & 0.711 & 2.865 \\
H3 & Quality of information form & 3 & 11173 & 0.472 & 0.150 & 0.553 & 2.324 & $\leq 0.002$ \\
H4 & Quality of information editing & 4 & 1037 & 0.537 & 0.135 & 0.787 & 2.536 & $\leq 0.001$ \\
H5 & Quality of information utility & 8 & 2675 & 0.459 & 0.070 & 0.727 & 2.281 & 0.003 \\
H6 & Event attention preference & 2 & 840 & 0.483 & 0.075 & 0.752 & 2.288 & 0.002 \\
H7 & Information environment heat & 3 & 678 & 0.415 & -0.177 & 0.923 & 1.569 & 0.117 \\
\hline
\end{tabular}

these factors. Therefore, it is assumed that the attention preference of $\mathrm{H} 6$ has verified the information adoption behavior of users in the spread of public opinion.

According to the degree of importance, the authority of the information source and the information editing quality have greater impacts on users' adoption behavior, and the effect of the information form quality and the incident on user attention preferences for users' information adoption behavior is moderate. In addition, the impacts on the reliability of information sources and information utility for public opinion spread have little effect on users' information behavior in the dissemination of public opinion. 
TABle 5: The results of the analysis.

\begin{tabular}{|c|c|c|c|c|c|c|}
\hline & \multirow{2}{*}{ Correlative variable } & \multirow{2}{*}{ Is it a public emergency? } & \multirow{2}{*}{ K } & \multirow{2}{*}{ Point estimation } & \multicolumn{2}{|c|}{$95 \% \mathrm{CI}$} \\
\hline & & & & & Lower & Upper \\
\hline \multirow{2}{*}{$H 1$} & \multirow{2}{*}{ Authority } & Yes & 5 & 0.368 & 0.330 & 0.405 \\
\hline & & No & 6 & 0.276 & 0.260 & 0.292 \\
\hline \multirow{2}{*}{$\mathrm{H} 2$} & \multirow{2}{*}{ Reliability } & Yes & 4 & 0.645 & 0.309 & 0.838 \\
\hline & & No & 2 & 0.247 & -0.119 & 0.554 \\
\hline \multirow{2}{*}{$H 3$} & \multirow{2}{*}{ Quality of information form } & Yes & 2 & 0.427 & -0.188 & 0.802 \\
\hline & & No & 1 & 0.035 & -0.045 & 0.115 \\
\hline \multirow{2}{*}{ H5 } & \multirow{2}{*}{ Quality of information utility } & Yes & 5 & 0.585 & 0.209 & 0.810 \\
\hline & & No & 3 & -0.022 & -0.772 & 0.754 \\
\hline \multirow{2}{*}{ H6 } & \multirow{2}{*}{ Event attention preference } & Yes & 1 & 0.510 & 0.284 & 0.450 \\
\hline & & No & 1 & 0.370 & 0.436 & 0.578 \\
\hline \multirow{2}{*}{ H7 } & \multirow{2}{*}{ Information environment heat } & Yes & 2 & 0.911 & 0.886 & 0.930 \\
\hline & & No & 1 & 0.295 & -0.089 & 0.602 \\
\hline
\end{tabular}

In summary, hypotheses $\mathrm{H} 1$ regarding authority, $\mathrm{H} 2$ regarding reliability, $\mathrm{H} 3$ regarding the quality of information form, $\mathrm{H} 4$ regarding the quality of information editing, $\mathrm{H} 5$ regarding the quality of information utility, and $\mathrm{H} 6$ regarding event attention preference are all verified. However, hypothesis $\mathrm{H} 7$ regarding information environment heat is not valid.

4.3. Moderator Analyses. According to the results in Table 3, since all the influencing factors are significant, the influence values of these variables come not only from the expected variables of sample error but also from the characteristics of different studies [55]; that is, there is a certain degree of heterogeneity between different studies. Heterogeneity is generally due to the different standards included in the studies and the different baseline levels and treatments of each research [26]. Considering the characteristics of the original literature, including the meta-analysis, this study took the type of event (whether it was a public emergency) as the moderator. The event types of different studies were divided into public emergencies and other events. Public emergencies refer to natural disasters, accident disasters, public health incidents, and social security incidents that occur suddenly, cause or may cause serious social harm, and require emergency response measures [56].

The results of the analysis of the effects of moderators are shown in Table 5.

When whether the event is a public emergency is used as a moderator variable, due to the small number of original studies, the event types of quality of information editing (H4) are nonpublic emergencies, so the variable is not included in the analysis results. The analysis results presented in Table 5 show that, among the other six variables, the point estimation when the event type is a public emergency is greater than the point estimation when the event type is not a public emergency. Therefore, we can infer that the event type has a moderating effect on users' information adoption behavior in the dissemination of public opinion. When the event type is a public emergency, the variable has a greater impact on users' information adoption behavior in public opinion spread.
4.4. Publication Bias. Publication bias refers to any situation that may lead to a systematic deviation between the accurate results and actual results in data collection, analysis, interpretation, publication, and review [57]. Publication bias may lead to inaccurate results. Therefore, it was necessary to test the publication bias of the collected literature. We used Egger's method to test the publication bias and judged the publication bias of the literature by identifying the significance between the regression intercept and 0 . The results are shown in Table 3. Because of insufficient parameters, H6 was unable to complete the Egger test, and the $p$ values for the other hypotheses were greater than 0.05 , indicating that there was no significant difference. There was no publication bias in the study, and the meta-analysis results did not deviate from the real results due to publication bias.

\section{Conclusions and Discussion}

Taking the user's information adoption behavior as the starting point, this study explored a series of variables that affect adoption behavior through meta-analysis. More specifically, we focused on the factors that have different degrees of influence on users' information adoption behavior in public opinion information dissemination. Now, we will discuss the results of the meta-analysis related to each hypothesis.

The authority and reliability of the information source have a significant correlation with the influence on users' information adoption behavior in public opinion spread, which is consistent with the conclusions of most studies. In the field of information systems, Jing [57] believed that the more followers you have, the more retweets you receive. Our research results show that the number of followers has a significant effect on forwarding. From the direction of the results, if users believe the authority of the information source and the degree of trust is high, they are willing to recognize its information utility and adopt it. Opinion leaders with authority and reliability and other core users have a great influence on the spread of public opinion; and their emotional tendencies, behavior, and speech lead the trend of the spread of public opinion to a certain extent. Therefore, in the network public opinion control process, it 
is necessary to strengthen the guidance of core users and give full play to the role of influential information sources to effectively control the public opinion communication behavior of users. For example, build a multibody coordinated response mechanism led by the government, and let the Internet Society, industry associations, law-abiding online opinion leaders, and other nongovernmental organizations play their due roles. Besides, a public opinion monitoring system can be built by identifying opinion leaders to prevent the spread of rumors and control the temporal development of public opinion. In addition, our research data show that the number of followers has a significant effect on forwarding. The results show that the number of fans is also one of the decisive factors of the influence of the information source. The more fans a publisher of public opinion information has, the more potential public opinion receivers it has, and the more likely its published information is to be browsed, forwarded, and given a thumbs up and receive comments. Therefore, in the process of public opinion supervision and guidance, in addition to opinion leaders, users with a large number of followers should also be taken as the main objects because these users can also become opinion leaders. Additionally, studies have shown that news media users have a greater influence on information audiences, so the government and enterprises should also pay attention to the management of the media. As an important information source for netizens, the media has greater reliability and influence than individual users. The public opinion supervision department should strengthen the management of the media to prevent the media from reporting on events untruthfully; furthermore, we should make good use of the reliability of the media to accurately control the developmental trend of public opinion and guide users to have rational cognition of online public opinion.

The quality of information form, the quality of information editing, and the quality of information utility in the perceived information quality have positive impacts on users' information adoption behavior. As long as users believe that the information content features can meet their information needs, the information editing format is more formal and complete, and the information can meet their needs and is useful to them, the users will be willing to adopt the information and forward it, comment on it, give it a thumbs up, and so on. Therefore, all kinds of news media, enterprises, and governments should fully understand information about users' preferences, such as by being good at using pictures, video, and other forms of information; paying attention to the standardization of information editing formats; releasing information promptly; and making public opinion expression information richer, more attractive, and timelier, thereby expanding the scopes of their audiences. In terms of the dynamic grasp of public opinion, relevant government departments can also take this perspective to make use of the intelligent service platform to release accurate and reliable emergency description information in the first time, deal with false information in a timely manner, appease the public panic, improve the credibility of the government, and guard against false information damaging the normal network order.
Event attention preference in the heat of public opinion events has a positive influence on users' information adoption behavior. If the general attention to and degree of discussion on a public opinion event are high, users are more inclined to recognize the utility of its information and adopt it. Previous studies have shown that, in terms of event types, public opinion events related to the environment, culture, and sports have relatively high heat; however, public opinion events related to anticorruption have relatively low heat, and the proportion of such public opinion events has been decreasing year by year since 2016. In terms of the initial causes of public opinion, the average popularity of largescale events and scientific and technological discoveries is relatively high. In different social environments, users' preferences for event attention are also different. The more attractive the features of public opinion events are, the more likely users will be to have the desire to participate. Therefore, to better address a public opinion crisis and the dynamic grasp of public opinion, the government public opinion supervision department should strengthen the ability to predict social security events, strengthen monitoring of events of a sensitive nature, and improve the control efficiency and crisis handling ability of online public opinion events based on understanding the attributes and characteristics of each event. A deep understanding of users' mentality and the trend of public opinion events, timely easing of the emotions of netizens, establishment of spread control and an early warning mechanism for crisis information in time, and avoidance of the explosion of public sentiment and the shock of the network public opinion field and other adverse effects can effectively promote the harmonious and healthy development of the network public opinion environment. However, the influence of information environment heat on users' information adoption behavior is not significant. It shows that the social discussion heat of the event can only affect users' information adoption behavior to some extent, but it cannot prove its usefulness. On the one hand, this proves that the relationship between information environment heat and users' information adoption behavior is not a simple linear relationship, which still needs further proof. On the other hand, it may be because the relevant pieces of literature and sample size were too small, and the reliability of the results needs to be tested by including more pieces of literature in a future study.

This study also has an important extended conclusion focusing on the moderating effect of the event type on users' information adoption behavior in the dissemination of public opinion. It was found that when the event type is a public emergency, the influence of various variables on users' information adoption behavior is more significant. That is, event types largely affect users' reception and adoption of public opinion information. Fully analyzing the types and characteristics of events and applying them to the source of public opinion information is a good strategy to solve the current dilemma of information dissemination.

5.1. Theoretical Implications. The purpose of this study is to summarize the influencing factors of users' information 
adoption behavior in the dissemination of public opinion through a comprehensive review and analysis of the relevant research on the dissemination of public opinion in China. At the theoretical level, the study revealed that the key influencing factors of users' information adoption behavior are the authority of information sources, reliability, quality of information form, quality of information form editing, quality of information form utility, event attention preference, information environment heat, and so on. This conclusion provides a new perspective and analysis method for studying users' information adoption behavior under the influence of public opinion information dissemination.

In addition, this study combines the effects of the existing literature to conduct quantitative research; uses the meta-analysis method to analyze the influencing factors of users' information adoption behavior in public opinion dissemination based on the ELM model; and proposes a model of the information adoption behavior of users in public opinion spread that combines information source reliability (authority and reliability), perceived information quality (quality of information form, quality of information form editing, and quality of information form utility), and the heat of public opinion event (event attention preference and information environment heat). This further enriches the ELM and reveals the path of users' information adoption behavior in public opinion spread, which is the innovation of our study. The study offers a new perspective for the study of users' information adoption behavior and expands the research scope of information adoption.

In addition, the theoretical framework of this study can provide good empirical support for the study of users' behavior in the spread of public opinion information based on a large number of empirical studies.

5.2. Practical Implications. The research conclusions can provide some support for the government management as well as the enterprise management and improve the decision-making capacity. If information publishers want to receive more attention and expand the scope of the content they publish, it is very important to improve their reliability and authority. Specifically, this can be achieved through identity verification, fan accumulation, and account level and reliability improvement. In addition, it is also necessary to pay attention to the information content, timing, and format. Reliable and rich information content, a formal information release format, and timely information release are more likely to be forwarded and spread by information recipients.

In addition, the continuous discussion, diffusion, and dissemination of public opinion information are inseparable from the leadership role of public opinion leaders. Information released by opinion leaders more easily spreads rapidly. If information cannot be controlled and managed in time, false information can be easily spread, and a public opinion crisis can even occur. In the management of public opinion information, after a public opinion incident breaks out, if opinion leaders make the correct judgments on the original incident or the truth of the incident and post it to social platforms, they can provide a large amount of correct guidance for a large number of network users. This can to some extent avoid unnecessary disputes about public opinion events. That is, by correctly guiding public opinion leaders to release content that has a significant impact on information, the development of public opinion information can move towards a benign direction. Therefore, in the identity authentication of opinion leaders, platform service providers should strictly control the authentication process during the identity authentication of opinion leaders to prevent some counterfeiters from passing authentication and breeding false information.

In addition, to maintain a good public opinion environment, the government can focus on fostering the sense of responsibility of social media users and severely crack down on fake news and harmful news to attract people's attention and improve the quality and the reliability of information. Users can be restrained through "education + law," and the behavior of information disseminators can be restrained through laws and regulations. In addition, humanized management can be achieved. Users can be referred to strategies to improve their information screening ability and information literacy, thereby preventing the secondary dissemination of passive information. Simultaneously, the government can use various means to expand the effect of positive topics. Before the dissemination of public opinion, standardized and reasonable topics can be set to actively guide public opinion in the correct direction. This can allow users to participate in the process of public opinion dissemination more reasonably.

The conclusions of this study also have economic value in the business field. On the one hand, enterprises can refer to the influencing factors of users' information adoption behavior to carry out network marketing and brand building. For example, be good at using pictures, videos, and other forms of information; pay attention to the standardization of information editing format. Enterprises can also combine the influence factors of the center path and the edge path to carry out product marketing and publicity and give full play to the role of media and opinion leaders, so as to better spread the corporate reputation. On the other hand, on the dynamic grasp of public opinion, the enterprise departments also may view this, using intelligent service platform, set up the media public opinion crisis early warning mechanism, strengthen the monitoring of sensitive events, improve the control efficiency of Internet public opinion events and crisis public relation capacity, and guard against potential threats, so as to ensure the stable development of the enterprise.

It is necessary to integrate multiple forces for the current network public opinion, and on the basis of maintaining the people's right to speak, give full play to the role of media, opinion leaders, and the government. Not only construct multiangle supervision mechanism to realize the construction of public opinion ecosystem, but also make full use of public opinion information, to create more economic and social benefits. 
5.3. Limitations. After addressing the theoretical and practical implications of our meta-analysis, we also need to recognize some important limitations of our study.

First, in the process of the elimination and inclusion of meta-analysis literature, due to the insufficient number of relevant variables in the literature, unavailable data, or a lack of data that could be converted into effect variables, some pieces of literature and samples were lost, making the sample data incomplete and possibly leading to deviations caused by incomplete data.

Furthermore, although the 20 included pieces of literature met the requirements of the meta-analysis, the number of empirical research studies on the factors that affect the spread of public opinion after comprehensive screening is still limited. With the development of public opinion spread, the amount of research literature has increased. In the future, the literature can be further expanded to improve the analysis of the influencing factors of users' information adoption behavior in public opinion spread to obtain a more comprehensive and convincing universal conclusion.

Finally, in addition to the influencing factors of users' information adoption behavior in the dissemination of public opinion, the interaction between various influencing factors and their different action mechanisms on users' information adoption behavior is worthy of attention in the future.

\section{Data Availability}

The data used to support the findings of this study are available from the corresponding author upon request.

\section{Conflicts of Interest}

The authors declare that there are no conflicts of interest regarding the publication of this paper.

\section{Acknowledgments}

This study was supported by the National Natural Science Foundation of China under Grant no. 71904106, the Ministry of Education of Humanities and Social Science Project of China under Grant no. 19YJC870019, the China Postdoctoral Science Foundation under Grant no. 2018M632688, and the Postdoctoral Science Foundation of Shandong Province under Grant no. 201903009.

\section{References}

[1] J. Urban and K. Bulkow, "Tracing public opinion online-an example of use for social network analysis in communication research," Procedia-Social and Behavioral Sciences, vol. 100, pp. 108-126, 2013.

[2] S. Q. Ji, Research on Mechanism of Opinion Evolution in Complex Network, Beijing University of Technology, Beijing, China, 2014.

[3] C. E. Shannon, "A mathematical theory of communication," Bell System Technical Journal, no. 27, pp. 379-423, 1948.

[4] Y. Zhang, X. L. Sun, and Q. H. Zhu, "Research on factors that influence microblog opinion communication based on elaboration likelihood model: taking Sina microblog as an example," Journal of the China Society for Scientific and Technical Information, vol. 33, no. 4, pp. 426-438, 2014.

[5] Y. L. Yin, Research on Influencing Factors Tweet Communication Effect of Hospital WeChat Based on Elaboration Likelihood Model, Huazhong University of Science \& Technology, Wuhan, China, 2019.

[6] J. W. Zhang, The Study on the Relationship between Negative Network Public Opinion and Passenger Repurchase Intention under the Situation of Flight Delays, Wuhan University of Technology, Wuhan, China, 2018.

[7] H. H. Liao, J. L. Jin, and Y. F. Wang, "Behavioral characteristics and relationship analysis of Weibo users in Internet public opinion event: taking "smog investigation: under the dome" of Sina Weibo as example," Information and Documentation Services, vol. 37, no. 3, pp. 12-18, 2016.

[8] D. X. Gu, Y. Zhang, Z. Z. Gu, and X. J. Yang, "Social network positive public opinions diffusion model: an empirical study based on ECM," Information Science, vol. 34, no. 4, pp. 29-34, 2016.

[9] D. Zhao, Research on Public Opinion Dissemination of MicroBlog Based on Information Ecology Theory in Mobile Environment, Jilin University, Changchun, China, 2017.

[10] H. Y. Chen, "Meta-analysis of influencing factors of mobile library user," Journal of Modern Information, vol. 37, no. 7, pp. 70-78, 2017.

[11] C. M. K. Cheung, M. K. O. Lee, and N. Rabjohn, "The impact of electronic word-of-mouth," Internet Research, vol. 18, no. 3, pp. 229-247, 2008.

[12] X. Y. Song, Research on Construction and Application of User's Information Adoption Behavior Model, Jilin University, Changchun, China, 2010.

[13] R. N. Geng, The Study of Influence Factors on Social E-Commerce Users' Information Adoption Behavior, Jilin University, Changchun, China, 2017.

[14] R. E. Petty, J. T. Cacioppo, and R. Goldman, "Personal involvement as a determinant of argument-based persuasion," Journal of Personality and Social Psychology, vol. 41, no. 5, pp. 847-855, 1981.

[15] R. E. Petty and J. T. Cacioppo, "The elaboration likelihood model of persuasion," Advances in Experimental Social Psychology, vol. 19, pp. 123-205, 1986.

[16] R. E. Petty, J. T. Cacioppo, and D. W. Schumann, "Central and peripheral routes to advertising effectiveness: the moderating role of involvement," Journal of Consumer Research, vol. 10, no. 2, pp. 135-146, 1983.

[17] L. E Pinsky and J. E. Wipf, "A picture is worth a thousand words practical use of videotape in teaching," Journal of General Internal Medicine, vol. 16, no. 15, pp. 805-810, 2000.

[18] G. H. Wang, Q. H. Zheng, Y. L. Wang, W. Q. Xiong, and $\mathrm{H}$. Xie, "Research on the characteristics and users' retweeting rules of top trending micro-blogs on Sina," Journal of Intelligence, vol. 33, no. 4, pp. 117-121, 2014.

[19] R. Ohanian, "Construction and validation of a scale to measure celebrity endorsers' perceived expertise, trustworthiness, and attractiveness," Journal of Advertising, vol. 19, no. 3, pp. 39-52, 1990.

[20] H. C. Kelman and C. I. Hovland, “"Reinstatement” of the communicator in delayed measurement of opinion change," The Journal of Abnormal and Social Psychology, vol. 48, no. 3, pp. 327-335, 1953.

[21] G. L. Patzer, "Source credibility as a function of communicator physical attractiveness," Journal of Business Research, vol. 11, no. 2, pp. 229-241, 1983. 
[22] E. McGinnies and C. D. Ward, "Better liked than right: trustworthiness and expertise as factors in reliability," Personality and Social Psychology Bulletin, vol. 6, no. 3, pp. 467-472, 1980.

[23] B. Krishnamurthy, P. Gill, and M. Arlitt, "A few chirps about twitter," in Proceedings of the First Workshop on Online Social Networks-WOSP '08, New York, NY, USA, August 2008.

[24] H. Bernardo, M. Romero Daniel, and F. Wu, "Social networks that matter: twitter under the microscope," First Monday, vol. 14, no. 1, 2008.

[25] J. L. Zhao and J. H. Cheng, "Empirical research of users' willingness to propagate microblogging public opinion based on perceptions, preferences, and involvement," Journal of the China Society for Scientific and Technical Information, vol. 33, no. 4, pp. 416-425, 2014.

[26] C. Lee, "Finding influentials based on the temporal order of information adoption in twitter," in Proceedings of the 19th International Conference on World Wide Web, WWW 2010, pp. 1137-1138, Raleigh, NC, USA, April 2010.

[27] S. J. Sullivan, A. G. Schneiders, C.-W. Cheang et al., "“What's happening?" a content analysis of concussion-related traffic on Twitter," British Journal of Sports Medicine, vol. 46, no. 4, pp. 258-263, 2012.

[28] G. Glass, "Primary, secondary, and meta-analysis of research," Educational Researcher, vol. 5, no. 10, pp. 3-8, 1976.

[29] S. J. Song, H. Yan, and H. X. Wang, "Meta-analysis of factors influencing Chinese college users' acceptance behavior for mobile libraries," Library and Information Service, vol. 63, no. 10, pp. 56-67, 2019.

[30] Y. Wei, The Communication Features Study of Enterprises Negative Network Public Opinion Basing on Sina Microblog, Anhui University, Hefei, China, 2013.

[31] R. X. Han, Research on Impact Factor of Internet Public OpinionPropagation-Based on Relevance Between Identityof Opinion Leaders and Events, Jilin University, Changchun, China, 2013.

[32] X. Zeng, X. Cheng, X. Y. Zhou, and C. N. Liu, "Study of public opinion dissemination mechanism on social networks based on dual-pathway model," Information Science, vol. 35, no. 6, pp. 29-33, 2017.

[33] Y. L. Wang and N. Jiang, "Public opinion survey, influence analysis and management countermeasures of popular microblogs-based on the perspective of young audiences," China Youth Study, vol. 11, pp. 50-55, 2013.

[34] X. M. Huang, Research on the Application of Agenda Setting Theory in thePseudo Perspective of WeChat PublicPlatform-Take JiangGe Case as an Example, Shandong University, Jinan, China, 2019.

[35] Y. Zhang, Research on the Influencing Factors of Online Public Opinion About Attention Degree and Governance Countermeasures, Huazhong Agricultural University, Wuhan, China, 2019.

[36] C. Q. Wu, "The Public Crisis Governance Research in Internet Environment," Central University of Finance and Economics, Beijing, China, 2016.

[37] J. H. Chen, "A study on users' participation behavior public opinion diffusion in mircroblog," Journal of Marine Science and Application, 2015.

[38] W. Hong, M. Sh, X. J. Hong, and X. J. Pu, "Influencing factors of netizens' micro-blog forwarding behavior in online public opinion on food safety-a case study of Shanghai Fuxi incident," China Population, Resources and Environment, vol. 26, no. 5, pp. 167-176, 2016.
[39] J. X. Cao, J. L. Wu, W. Shi, B. Liu, X. Zhen, and J. Z. Luo, "Sina microblog information diffusion analysis and prediction," Chinese Journal of Computers, vol. 37, no. 4, pp. 779-790, 2014.

[40] P. Hou and H. Y. Liu, "Analysis on the influencing factors of social media users' public opinion communication behavior," Electronic Business, vol. 1, pp. 51-59, 2019.

[41] B. B. Wang, Research of Emergency Information Sharing of Extreme Events in Online Soc, Shanghai University of Engineering Science, Shanghai, China, 2015.

[42] Z. K. Wu, "The research of factors affecting public opinion guidance in food safety crisis," Journal of Shanghai Jiaotong University, 2012.

[43] Q. K. Wang, "Study on the influence factors of netizens'behavior of spreading ideological public opinion information," Journal of Nanchang University, 2020.

[44] J. H. Li and X. R. Chang, "The influence factors of knowledge transfer: a meta-analytic review," Studies in Science of Science, vol. 31, no. 3, pp. 394-406, 2013.

[45] Y. Hu, W. Y. Xiao, and C. Wang, "Research on the construction of micro-blog information quality evaluation indicator system," Information Science, vol. 35, no. 6, pp. 44-50, 2017.

[46] S. Bi, "Antecedents of governmental microblog reliability," Journal of Shanghai Jiaotong University, 2013.

[47] S. Y. Jiang, D. Y. Chen, G. P. Pang, M. L. Wu, and L. X. Wang, "Research review of information reliability analysis on microblog," Library and Information Service, vol. 57, no. 12, pp. 136-142, 2013.

[48] F. Q. Jiang, "Research on influencing factors of college students' online health information seeking behaviors from-the perspective of information ecology," Journal of Central China Normal University, 2020.

[49] Z. Y. Mo, "Research on evaluation of microblog information content quality and its influence on user's utilization," Journal of Wuhan University, 2014.

[50] Y. Feng and R. Y. Zhang, "A research on evaluation of microblog information quality based on user experience," Researches In Library Science, no. 9, pp. 62-67, 2014.

[51] J. Li, X. J. Qi, and M. H. Chen, "Understanding the impact of perceived information quality on information acquisition and information adoption," Information Science, vol. 33, no. 3, pp. 123-129, 2015.

[52] J. H. Cheng, "A study on users' participation behavior of public opinion diffusion in microblog," Journal of Harbin Engineering University, 2015.

[53] D. Zhao, "Research on public opinion dissemination of micro-blog based on Information ecology theory in mobile environment," Journal of Jilin University, 2017.

[54] D. Zhao, X. W. Wang, M. M. Xiang, and M. Q. Yang, "Model of micro-blog public opinion dissemination trend under the new media environment: an information ecology perspective," Journal of Information, vol. 35, no. 10, pp. 173-180, 2016.

[55] S. J. Cao and Z. H. Wang, "A meta-analysis research on antecedents and their moderating factors of knowledge sharing intentions and behavior in online communities," Library and Information Service, vol. 62, no. 8, pp. 74-83, 2018.

[56] The State Council, Law of the People's Republic of China on Emergency Response, The State Council, Beijing, China, 2007.

[57] X. L. Jin, H. H. Feng, and Z. Y. Zhou, "An empirical study on healthcare information diffusion in WeChat moments," BehaviorJournal of Management Science, vol. 30, no. 1, pp. 73-82, 2017. 